\title{
Representação das variedades do português nos documentos norteadores para o ensino/aprendizagem de Português Língua Estrangeira
}

\author{
Mercedes Sebold* \\ Ana Carolina Monteiro Freitas Henriques**
}

Resumo

O presente estudo tem por objetivo analisar a representação das variedades do português nos documentos norteadores para o ensino/aprendizagem de Português Língua Estrangeira (doravante PLE). No contexto de ensino de PLE fora dos países que têm o português como língua oficial, encontramos um grande número de professores que não têm formação linguística específica. O mercado de trabalho promissor em alguns países absorve falantes de outras línguas que fizeram cursos de curta duração ou ainda profissionais de outras áreas que têm o português como língua materna. Tais profissionais nem sempre estão familiarizados com noções como língua padrão, norma culta, variação linguística. Nesses contextos, os documentos norteadores podem oferecer subsídios para o planejamento de cursos, avaliações e até mesmo como única fonte de referência teórica de professores com pouca ou insuficiente formação teórica. Cabe propor então a seguinte questão: como tais documentos norteadores contribuem para dar visibilidade às variedades do português? Esta é a pergunta central a que nos propusemos a responder. Para tal, analisamos alguns documentos voltados para a sistematização de conteúdos

\footnotetext{
* Universidade Federal do Rio de Janeiro (UFRJ). Doutora em Linguística pela Universidade Federal do Rio de Janeiro. Professora Associada de Língua Espanhola da Faculdade de Letras (UFRJ). Professora do Programa de Pós-Graduação em Letras Neolatinas (UFRJ). Orcid: https://orcid.org/0000-0002-0035-3338.

** Universidade Federal do Rio de Janeiro (UFRJ). Mestre em Letras Neolatinas pela Universidade Federal do Rio de Janeiro. Doutoranda do Programa de Pós-Graduação de Letras Neolatinas da Faculdade de Letras da Universidade Federal do Rio de Janeiro. Orcid: https://orcid.org/0000-0002-6956-3296.
} 
para o ensino/aprendizagem de PLE. Os resultados mostram que, na maioria das vezes, tais documentos ainda oferecem escassa informação que poderia fomentar a representação das variedades do português na sala de aula de PLE.

Palavras-chave: Português Língua Estrangeira (PLE). Material didático. Variação linguística. Políticas linguísticas.

\title{
Representation of the Portuguese varieties in the guiding documents for the teaching/learning of Portuguese as a foreign language
}

\begin{abstract}
The present study aims to analyze the representation of the varieties of Portuguese in the guiding documents for teaching / learning Portuguese as a Foreign Language (henceforth PLE). In the context of teaching PLE outside countries that have Portuguese as their official language, we find a large number of teachers who do not have specific language training. The promising job market in some countries absorbs speakers of other languages who have taken short courses or even professionals from other areas who have Portuguese as their mother tongue. Such professionals are not always familiar with notions such as standard language, cultured norm, linguistic variation. In these contexts, the guiding documents can offer subsidies for the planning of courses, assessments and even as the only source of theoretical reference for teachers with little or insufficient theoretical training. It is worth asking the following question: how do such guiding documents contribute to giving visibility to the varieties of Portuguese? This is the central question that we set out to answer. To this end, we analyzed some documents aimed at the systematization of content for the teaching / learning of PLE. The results show that, in most
\end{abstract}


cases, such documents still offer little information that could promote the representation of the Portuguese varieties in the PLE classroom.

Keywords: Portuguese as a Foreign Language (PLE). Teaching material. Linguistic variation. Linguistic policies.

Recebido em: 05/03/2021 // Aceito em: 30/03/2021. 


\section{Introdução}

Como muitas outras línguas naturais, a expansão do português se deu inicialmente por meio de uma relação de imposição entre colonizador e colonizado. Em momentos posteriores da história, como quando foi assinada, em 1991, a criação do Mercado Comum do Sul (Mercosul), parecia que o ensino do português poderia ser alavancado como contrapartida ao ensino do espanhol no Brasil, mas não foi o que aconteceu (ou pelo menos na mesma proporção do espanhol).

Mais do que conhecer os países que falam o português, é relevante dar voz às diferentes variedades que coexistem dentro de cada um dos países que têm essa língua como sua. Mas como estão representadas essas idiossincrasias do português no material didático de Português Língua Estrangeira (doravante PLE)?

Nos materiais didáticos para o ensino do espanhol como língua estrangeira, por exemplo, parece predominar a variedade peninsular (que, na verdade, não é só uma) e as demais variedades muitas vezes são desprestigiadas como variedades de menor status. Isso também ocorre no contexto de PLE?

Esperamos trazer algumas respostas para o contexto de ensino/aprendizagem do PLE. Escolhemos analisar documentos norteadores por entender que tais documentos são as referências para produção de materiais, elaboração de avaliações e também podem ser muitas vezes a única fonte de informação para aqueles que ensinam português como língua estrangeira. Este artigo está organizado da seguinte forma: primeiro tratamos da variação no português. Posteriormente, analisamos a representação das variedades do português no Documento-base 
Representação das variedades do português nos documentos norteadores para o ensino/aprendizagem de Português Língua Estrangeira

do Exame Celpe-Bras (BRASIL, 2020) e nos três volumes da coleção do Ministério das Relações Exteriores (2020a; 2020b; 2020c) dirigidos ao ensino/aprendizagem de PLE e, finalmente, apresentamos nossas conclusões.

\section{Variação no português}

Iniciamos este artigo partindo de algumas questões que não necessariamente têm uma resposta, mas parecem ser o pano de fundo do tema que nos mobilizou para a escrita deste texto, qual seja: a representação das variedades do português no processo de ensino/aprendizagem como LE.

No que diz respeito ao português, não começaremos com a clássica informação que diz respeito ao número de falantes do português para justificar sua importância ou a relevância de seu ensino. Conforme mencionamos na introdução, mesmo com o advento do Mercosul, o português não teve políticas linguísticas uniformemente sérias que ajudassem a sua divulgação, entretanto, em contrapartida, o interesse por essa língua é crescente.

Ao retomar os estudos da linguagem, Faraco (2008, p. 31) propõe que "nenhuma língua é uma realidade unitária e homogênea" e vai mais além ao afirmar que "uma língua é constituída por um conjunto de variedades". Ao fazer tal afirmação, o autor atribui à língua uma constituição intrinsecamente heterogênea. Interessa-nos seu exemplo ao afirmar que, quando nos referimos ao português, tal designação não se refere a "um objeto empírico uno, homogêneo, claramente delimitável e objetivamente definível por critérios apenas linguísticos" (FARACO, 2008, p. 32). 
Considerando o contexto de variação do português do Brasil (doravante PB), Carvalho e Bagno (2017) afirmam que muitos estudos realizados nos últimos tempos revelam um panorama das principais variedades regionais e/ou sociais do PB. Os autores destacam, por exemplo, com relação às contribuições relativas ao sistema pronominal, que:

(1) com relação aos pronomes de $2^{\mathrm{a}}$ pessoa do singular: existem seis subsistemas em que os usos de "tu" e "você" se combinam com a morfologia verbal.

(2) com relação aos pronomes de $1^{\text {a }}$ pessoa do plural: concorrem duas variantes: a forma "nós" e a forma "a gente";

Carvalho e Bagno (2017) também reconhecem que vêm sendo produzidas obras descritivas que consideram grandes corpora de língua falada e escrita: Neves (2001), Azeredo (2008), Perini (2010), Castilho (2010), Bagno (2012), o projeto Gramática do português culto falado no Brasil (apud CARVALHO; BAGNO, 2017). Mas os autores apontam a grande contradição se se considera que tais estudos não são levados em conta e, portanto, seus resultados não aparecem no material didático para o ensino de PLE. Acrescentamos ainda que, provavelmente, também sejam desconsiderados nas aulas e muitas vezes até desconhecidos pelos próprios professores.

A crítica feita por Carvalho e Bagno (2017) aos livros didáticos para o ensino de PLE publicados no Brasil é bastante contundente:

Os livros didáticos de português brasileiro, no entanto, apesar de serem publicados no Brasil e terem por obrigação representar a realidade linguística e cultural brasileira, ainda se atêm a prescrições das gramáticas tradicionais, as quais tomam como referência a produção de clássicos consagrados da literatura não somente brasileiros, com também portugueses. (CARVALHO; BAGNO, 2017, p. 30). 
Representação das variedades do português nos documentos norteadores para o ensino/aprendizagem de Português Língua Estrangeira

Compartilhamos com os autores a ideia de que, em contextos de não imersão do aprendiz, o input oferecido pelo material didático deva fazer referência à língua em uso das comunidades que têm o português como língua oficial. Em seu estudo, Carvalho e Bagno (2017) analisam manuais publicados no Brasil a partir de 2000. Na crítica que fazem a um dos manuais analisados (BV: Bem-vindo! A língua portuguesa no mundo da comunicação), no que diz respeito à forma como apresenta os pronomes pessoais, destacam que faz uso de textos não autênticos (aos quais chamam de "pseudotextos") e que apresenta incorreções como informar que as formas "você" e "a gente" não são pronomes pessoais, mas formas de tratamento no PB.

Pensemos na língua que é nosso objeto de discussão neste momento: o português. Esta é a língua de diferentes comunidades linguísticas (no Brasil, dentro de um mesmo estado, temos inúmeras comunidades linguísticas, em Portugal também e nos países que foram colônias de Portugal também). E cada comunidade linguística se caracteriza por apresentar um determinado conjunto de normas. Mas nem todas parecem estar legitimadas da mesma forma. Algumas parecem merecer mais status do que outras. Vemos isso todos os dias nos meios de comunicação, nas artes... Quando alguma norma fora do eixo das grandes capitais aparece como protagonista, chama a atenção mais por ser exótica do que por ser uma legítima representante de uma das normas do português.

Voltamos a falar sobre a norma e o fazemos retomando Faraco (2008). que se refere à norma como fator de identificação do grupo: "Podemos afirmar que o senso de pertencimento inclui o uso das formas de falar características das práticas e 
expectativas linguísticas do grupo.” (FARACO, 2008, p. 41). Tal afirmação nos leva à próxima etapa deste artigo: o contexto de ensino-aprendizagem de PLE. Os documentos norteadores que servem de fonte de informação e formação dos professores de PLE trazem informação suficiente sobre as normas do português? Alguma norma é privilegiada em detrimento das demais? Tal recorte pode contribuir para disseminação do preconceito e do não reconhecimento das demais normas?

Estes são apenas questionamentos iniciais que dão uma pequena amostra da tarefa difícil e árdua de representar uma língua, diferentes normas, diferentes formas de falar. Mas não diminui a responsabilidade daqueles que ocupam lugares de prestígio e detêm algum poder de fazer diferente e fazer da melhor forma possível.

Entendemos que os documentos norteadores para o ensino de PLE são ações que constituem uma política linguística e, como tal, indicam direções para novas ações. Por isso, partimos da definição de Calvet (2002) para política linguística. $\mathrm{O}$ autor propõe que se trata de "um conjunto de escolhas conscientes referentes às relações entre língua(s) e vida social e de planejamento linguístico, a implementação concreta de uma política linguística, de certo modo, a passagem ao ato". (CALVET, 2002, p. 133).

Sobre o plurilinguismo que caracteriza nosso mundo, Calvet (2002) propõe que há dois tipos de gestão de tal plurilinguismo: aquele que emana das práticas sociais e o que é resultado da intervenção sobre tais práticas. Mas esse mesmo autor propõe ainda que existe outra abordagem dos problemas do plurilinguismo que seria a abordagem do poder. 
Representação das variedades do português nos documentos norteadores para o ensino/aprendizagem de Português Língua Estrangeira

Seguindo a linha de pensamento de Calvet (2002), os Estados podem promover uma língua ou modificar seu status ou suas funções sociais. Tal reflexão nos parece de extrema importância, uma vez que entendemos que uma política linguística e as suas respectivas ações relativas à expansão do português fora de seus países deveriam contemplar a totalidade de suas variedades, por exemplo.

Tal direcionamento permitiria que um aprendiz de PLE fosse exposto à amplitude das variedades dos diferentes países que têm o português como língua oficial e não tivesse que limitar sua aprendizagem à variedade que, por imposição, seria a de maior prestígio ou de maior status ou aquela que foi apresentada como tal ao professor por ocasião de seu processo de aprendizagem.

Interessa-nos o conceito de representação na perspectiva pós-estruturalista, porque, segundo Silva (2000, p. 89), "incorpora todas as características de indeterminação, ambiguidade e instabilidade atribuídas à linguagem". O autor propõe que representar significa determinar a identidade. Assumimos, seguindo a linha de pensamento de Silva (2000), que aqueles que detêm o poder de representar são os que definem e determinam a identidade.

No caso dos documentos norteadores para o ensino do PLE, representaro português semrepresentarsuas diferentes variedades pode não servir para definir o português ou pode ser representálo de maneira parcial ou até mesmo reducionista. Considerando tais escolhas conscientes esperadas nas políticas linguísticas, pareceu-nos relevante investigar que direcionamentos podemos levantar em alguns dos documentos norteadores elaborados com vistas ao contexto de ensino-aprendizagem de PLE. 


\section{Metodologia}

Considerando os objetivos definidos anteriormente para este artigo, optamos por uma metodologia qualitativa e quantitativa (embora entendamos que a quantidade de ocorrências que poderemos levantar não será exaustiva).

Buscamos levantar ocorrências de referências às variedades do $\mathrm{PB}$ em documentos norteadores para o ensino de PLE. Comporão nosso corpus para esta análise os seguintes documentos, ordenados pelo título:

Quadro 1 - Corpus de análise

\begin{tabular}{|l|l|}
\hline \multicolumn{1}{|c|}{ SIGLA } & \multicolumn{1}{c|}{ TÍTULO } \\
\hline DBE & Doc.-base do Exame Celpe-Bras \\
\hline PLELOE & $\begin{array}{l}\text { (i) Português como lingua estrangeira para países de } \\
\text { lingua oficial espanhola }\end{array}$ \\
\hline PLELH & (ii) Português como lingua de herança \\
\hline PLEILOP & $\begin{array}{l}\text { (v) Português como língua intercultural para países de } \\
\text { lingua oficial portuguesa }\end{array}$ \\
\hline
\end{tabular}

Fonte: Elaborado pelas autoras.

Estabelecemos como critério de seleção dos materiais o corte temporal, já que os quatro documentos têm como data de publicação o ano de 2020. Interessa-nos avaliar se, por se tratar de versões bem recentes, já foram incorporados novos aspectos $\mathrm{e}$, principalmente, se encontraremos referências às variedades do PB. 
Representação das variedades do português nos documentos norteadores para o ensino/aprendizagem de Português Língua Estrangeira

\section{Documentos norteadores para o ensino/aprendizagem de PLE}

\subsection{Documento-base do Exame Celpe-Bras (versão 2020)}

É recorrente em artigos da área a afirmação de que faltam parâmetros brasileiros para o ensino de PLE. Schoffen e Martins (2016) corroboram esse dado. Segundo os autores, a ausência de documentos que possam pautar o ensino de PLE faz com que se busquem orientações para o ensino em outras ações da área (SCHOFFEN; MARTINS, 2016, p. 2). Como exemplo de tal afirmação, destacam a importância do Exame Celpe-Bras, que vem atuando na condição de "elemento direcionador" dos processos educacionais. Diante do exposto, pareceu-nos relevante partir do Documento-base do Exame Celpe-Bras (doravante DBE), versão 2020.

Nessa versão mais recente, são retomados alguns aspectos da história do exame, tais como a Portaria $\mathrm{n}^{\circ} 1.787$, de 26 de dezembro de 1994, na qual já se afirmava sua vocação de direcionar o ensino de português: "Oferecer um instrumento com potencial para redirecionar o ensino de português, tanto no Brasil quanto no exterior, visto que exames de proficiência podem ser eficientes mecanismos de política linguística." (BRASIL, 2020, p. 17).

Os autores também destacam a relevância da ação de criação de um exame de proficiência do Brasil e, por isso, se constitui como um instrumento de política linguística do Estado brasileiro. Schoffen e Martins (2016) afirmam que tal ação contribuiu para desconstruir a ideia de que o português do Brasil seria uma variedade menor em relação ao português europeu. 
Diante de todo o exposto, entendemos que o DBE poderia servir de importante referência para diferentes elementos que constituem o contexto de ensino-aprendizagem de português, tais como desenho de material didático, avaliações, entre outros. Mas que referências às variedades do $\mathrm{PB}^{1}$ podemos esperar na definição das pautas de avaliação descritas nesse documento? Foi essa a pergunta que definimos para orientar nossa análise.

Cabe aqui abrirmos um pequeno parênteses para esclarecer que não é objetivo deste artigo desmerecer ou deslegitimar o Exame de Proficiência Celpe-Bras, que tem cumprido seus objetivos de avaliar, considerando os mais atuais conceitos de proficiência, bem como definir pautas que se aproximem ao máximo dos contextos que serão exigidos daqueles que se apresentam para obter tal diploma de proficiência. Com relação a esse aspecto, cabe ainda reconhecer que o exame vem se adequando às necessidades daqueles que precisam obter tal certificação para dar continuidade à sua vida acadêmica ou profissional.

Entretanto, talvez não tenhamos de esperar de tal ação nada além daquilo a que se propõe ser: um exame que avalia proficiência, proficiência daqueles que usarão a língua no seu dia a dia, ou seja, nas suas interações principalmente profissionais. Cabe sim questionar como um documento regulador de uma fase final do processo de aprendizagem, a avaliação, pode ser o único a orientar as demais fases anteriores.

Nessa linha de pensamento, fomos buscar no documento referências às variedades do PB. Essa versão mais recente do documento tem como principal objetivo apresentar as alterações feitas na estrutura do exame e parâmetros de avaliação

\footnotetext{
1 Embora reconheçamos a limitação de alguns rótulos na referenciação das línguas, neste artigo, optamos por fazer tal referência com o termo português do Brasil, considerando sua produtividade nos estudos de descrição dessa língua.
} 
Representação das variedades do português nos documentos norteadores para o ensino/aprendizagem de Português Língua Estrangeira

apresentados no capítulo 3 ("Estrutura do exame e parâmetros de avaliação"). Selecionamos alguns fragmentos que podem ser avaliados do ponto de vista do silenciamento no que diz respeito às variedades do $\mathrm{PB}$.

Ao apresentar a definição de estratégias comunicativas considerando a abordagem de Niederauer (2014), destacamos a definição de pronúncia, assumida pelo documento: "capacidade de produzir os sons para a produção de sentido, o que implica o domínio de aspectos não apenas segmentais, mas também suprassegmentais (em particular, acentuação, ritmo, entonação)" (BRASIL, 2020, p. 48).

Entendemos que, para as finalidades do documento, tal definição daria conta do que mais adiante será explicitado nos quadros que apresentam as grades analíticas de avaliação da parte oral do exame.

$\mathrm{Na}$ página 51 do referido documento, encontramos, no Quadro 4, o detalhamento do item Pronúncia para fins de avaliação: "Pronúncia (sons, ritmo e entonação) adequada." Fica claro pela descrição apresentada que será do interesse do avaliador o grau de interferência (o documento se refere a "eventuais marcas de outras línguas") da língua materna no português. Não poderíamos esperar aqui, nem mesmo em uma nota de rodapé, que se fizesse menção à necessidade de avaliar a habilidade do candidato de compreender inúmeros enunciados relativos a diferentes variedades do PB. Esse argumento por si só seria suficiente para justificar que a ação do exame está bem definida e cumpre com seus objetivos. O que não está definido e necessita de uma ação específica são os documentos norteadores para o ensino de PLE. 
Embora tivéssemos consciência, desde o início da análise desse documento, de que a finalidade de um descritor de exame não necessariamente seja a mesma de um documento norteador para o ensino, encontramos na versão analisada uma referência que poderia sim ser ampliada de modo a contemplar uma visão mais atualizada de variação. Encontramos no Quadro 8 (BRASIL, 2020, p. 62), que trata dos Eixos de sub-habilidades das partes escrita oral do Exame Celpe-Bras, na descrição da parte oral, o seguinte objetivo: "Utilizar sons, ritmo e entonação da língua portuguesa."

Na definição desse objetivo, entendemos que se optou por uma generalização de língua que parece neutralizar a variação do PB. Embora uma especificação que considerasse as variedades do PB não fosse objeto de avaliação, entendemos que, dada a natureza de representação do documento, tal referência poderia ter sido feita.

Mais uma vez, reforçamos que nosso objetivo, ao analisar o DBE, não é em absoluto deslegitimar essa ação, que tem ganhado reconhecimento desde a portaria que a formalizou. Pretendemos sim problematizar a ausência de documentos orientadores específicos para o ensino de PLE.

Essa breve análise desse documento nos permite reconhecer que o desenho do exame de proficiência é bem definido, bem como as pautas de avaliação são bem descritas, de modo que aqueles que estejam envolvidos no processo - avaliadores, professores preparadores e aqueles que se inscrevem para realizar o exame - tenham a real visão de como se dará a avaliação da proficiência e quais os parâmetros aplicados. Entretanto, também verificamos o silenciamento de pautas para o processo anterior à avaliação, ou seja, de aprendizagem de PLE (que, como já 
Representação das variedades do português nos documentos norteadores para o ensino/aprendizagem de Português Língua Estrangeira

havíamos mencionado anteriormente, não constitui em absoluto a finalidade do documento em questão).

\subsection{Propostas curriculares para ensino de português no exterior}

Como havíamos apontado anteriormente, a ausência de propostas curriculares específicas para o ensino de português no exterior sempre foi uma questão comentada por diversos autores (SCHOFFEN; MARTINS, 2016; FRANCO, 2019). A fim de preencher essa lacuna, o Ministério das Relações Exteriores (MRE) e a Fundação Alexandre de Gusmão (Funag) publicaram, em maio de 2020, a coleção Propostas curriculares para ensino de português no exterior, composta pelos seguintes títulos: (i) Português como língua estrangeira para países de língua oficial espanhola; (ii) Português como língua de herança; (iii) Literatura para o ensino de português; (iv) Português para praticantes de capoeira; (v) Português como língua intercultural para países de língua oficial portuguesa.

As publicações, segundo os autores, visam a harmonizar o conteúdo dos cursos de português no exterior pertencentes à rede de ensino do Itamaraty, contribuindo para o fortalecimento destes e aprimorando seu potencial como instrumento de política linguística e cultural do Brasil.

Entendemos que tais publicações constituem importantes ações de política linguística que já vinham há muito sendo requeridas pelos diferentes âmbitos ligados ao processo de ensino-aprendizagem de PLE. Neste artigo, selecionamos como objeto de nosso estudo os títulos (i), (ii) e (v). 
3.2.1 Português como língua estrangeira para países de língua oficial espanhola

A proposta apresentada no título Português como língua estrangeira para países de língua oficial espanhola (MINISTÉRIO DAS RELAÇÕES EXTERIORES, 2020b) rechaça a abordagem meramente sistemática de língua e destaca a importância do desenvolvimento de diferentes capacidades que permitam que o aluno produza e interprete textos de diferentes gêneros discursivos.

O documento é norteado pela perspectiva dialógica da linguagem (BAKHTIN, 1979/2003). Tal corrente entende a língua como um diálogo inacabável formado a partir de diversas enunciações não inéditas, já habitadas por diferentes entonações e avaliações que ganham um novo sentido pelo locutor. Em síntese, essa perspectiva defende que o assunto de que se fala "está amarrado e penetrado por ideias gerais, por pontos de vista, por apreciações de outros e por entonações" (BAKHTIN, 1975/2002, p. 86).

A partir dessa noção, o volume reafirma a necessidade de entender a língua como meio de (re)construção de sentidos, buscando um trabalho pedagógico que favoreça o discurso diverso e que contribua para a formação intercultural dos aprendizes. Nesse sentido, o documento ainda ressalta a importância de uma visão que não limite o português a um instrumento de comunicação, mas que valorize seus aspectos políticos e culturais.

A temática da proximidade tipológica entre o português e o espanhol também é abordada no documento. Os autores destacam a mobilização de diferentes gêneros discursivos e a abordagem 
Representação das variedades do português nos documentos norteadores para o ensino/aprendizagem de Português Língua Estrangeira

contrastiva que a referida proximidade entre as línguas facilita, contudo rechaçam a ideia de tal abordagem como principal norteador do currículo.

Em sua segunda seção, o título em questão apresenta uma proposta de harmonização curricular dos cursos de português em países de língua oficial espanhola, indicando a necessidade do estabelecimento de níveis claros de proficiência e de uma estrutura comum aos cursos no que tange a questões como o número de níveis, carga horária e nomenclatura (MINISTÉRIO DAS RELAÇÕES EXTERIORES, 2020b, p. 23).

No que se refere aos níveis de proficiência, o documento considera, a partir de uma equivalência aproximativa, os parâmetros do Certificado de Proficiência em Língua Portuguesa para Estrangeiros (Celpe-Bras) e do Quadro Europeu Comum de Referência para as Línguas (QECR).

O QECR é um padrão de avaliação dos níveis de proficiência de uma determinada língua adotado internacionalmente. Por meio da descrição de habilidades a serem desenvolvidas e da delimitação de objetivos para cada nível, o documento serve como um instrumento de unificação no que se refere ao ensino de línguas estrangeiras.

Entendemos que uma generalização da natureza do QECR pode ser produtiva para um modelo de exame de proficiência, mas não para um documento que trate, de modo mais específico, do processo de ensino-aprendizagem. Além de não atentar para as especificidades de cada língua e seus aprendizes, tal generalização pode provocar interpretações diferentes ao estabelecer objetivos pouco claros como podemos observar em sua descrição do nível B2. 
É capaz de compreender as ideias principais em textos complexos sobre assuntos concretos e abstratos, incluindo discussões técnicas na sua área de especialidade. É capaz de comunicar com um certo grau de espontaneidade e de à-vontade com falantes nativos, sem que haja tensão de parte a parte. É capaz de exprimir-se de modo claro e pormenorizado sobre uma grande variedade de temas e explicar um ponto de vista sobre um tema da atualidade, expondo as vantagens e os inconvenientes de várias possibilidades. (CONSELHO DA EUROPA, 2001, p. 49, grifos nossos).

Expressões como "certo grau de espontaneidade" e "sem que haja tensão" são definições genéricas que podem ser pouco produtivas no que se refere ao ensino de línguas. Ademais, nos parece importante destacar que os parâmetros do QECR podem não corresponder a diferentes ambientes sociais fora do eixo europeu. Quetz (2003, p. 152 apud NUNES; LORKE, 2011, p. 44) comenta que uma tarefa simples associada a níveis iniciais como fazer compras pode exigir maior competência linguística do que retirar o produto da prateleira e ir ao caixa, como é de praxe em supermercados europeus. Pode haver a necessidade de negociar preços, questionar a respeito da disponibilidade de uma determinada mercadoria, etc.

Ainda que tenha os parâmetros do QECR e do Celpe-Bras como base, o documento analisado ressalta a necessidade de um plano curricular que compreenda as especificidades linguísticas e culturais entre o português e o espanhol bem como o Brasil e os países hispanofalantes.

A respeito dos aspectos metodológicos da proposta curricular - para os cursos regulares de português em países de língua oficial espanhola - apresentada no documento, destacamos o trecho a seguir a fim de retomar o viés discursivo que norteia a proposta: 
Representação das variedades do português nos documentos norteadores para o ensino/aprendizagem de Português Língua Estrangeira

Em relação a aspectos educacionais e metodológicos, a proposta mostra-se alinhada a tendências contemporâneas de ensino-aprendizagem de línguas, norteando-se por concepções que trazem destaque à compreensão de língua(gem) sob perspectiva discursiva e ao seu ensino como atividade reflexiva e como experiência que favorece o desenvolvimento de um movimento intercultural abrangente. (MINISTÉRIO DAS RELAÇÕES EXTERIORES, 2020b, p. 10).

O currículo apresentado pelo título é estruturado, com base em Serrani (2010), em três dimensões hierarquicamente organizadas, como podemos observar na figura a seguir:

Figura 1 - Hierarquia dos componentes curriculares

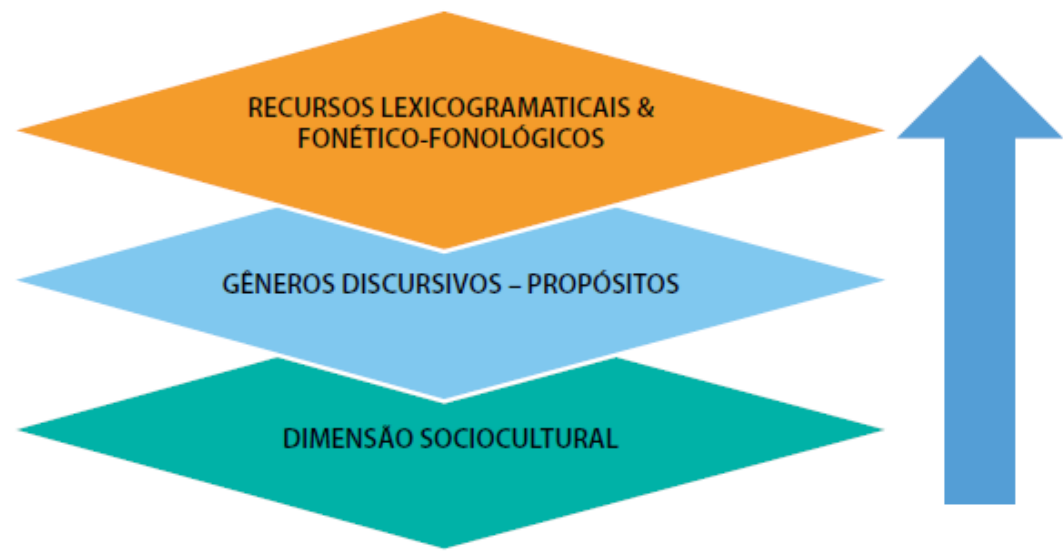

Fonte: MINISTÉRIO DAS RELAÇÕES EXTERIORES, 2020b, p. 35.

Em síntese, propõe-se que o trabalho pedagógico tenha a dimensão sociocultural como ponto de partida. Para tanto, o documento sugere o recurso de unidades temáticas ou projetos pedagógicos. Nesse sentido, o documento justifica a amplitude da dimensão sociocultural proposta de cada nível com a necessidade de viabilizar diferentes recortes e não comprometer 
a flexibilidade necessária para contemplar especificidades do contexto de cada instituição e/ou turma (MINISTÉRIO DAS RELAÇÕES EXTERIORES, 2020b, p. 36-37).

Os quadros curriculares propostos no documento classificam os conteúdos em cinco categorias, a saber: dimensão sociocultural; gêneros discursivos (orais, escritos, multimodais); propósitos; recursos lexicogramaticais; recursos fonéticofonológicos.

Não se pode dizer que o documento desconsidera as variedades do PB, contudo é importante destacar que a abordagem a respeito do tema é bastante reduzida e que determinados pontos parecem indicar uma tendência à homogeneização da língua.

Na proposta apresentada para o curso de Português Básico I, um dos pontos citados na categoria de recursos fonéticofonológicos diz respeito à "sensibilização para o ritmo e a prosódia em português brasileiro" (MINISTÉRIO DAS RELAÇÕES EXTERIORES, 2020b, p. 39), entretanto não há nenhuma menção às variações existentes nesse aspecto, o que pode indicar a valorização de uma variedade tida como padrão em detrimento de outras.

Apenas no currículo proposto para o curso de Português Intermediário II começam a aparecer alguns pontos referentes à variação. A seguir, destacamos alguns destes citados na categoria de recursos fonético-fonológicos (MINISTÉRIO DAS RELAÇÕES EXTERIORES, 2020b, p. 45):

- Marcas fonético-fonológicas típicas de variedades não prestigiadas do português;

- Aspectos fonético-fonológicos típicos de variedades não prestigiadas do português;

- Diferenças regionais na pronúncia do português brasileiro. A questão da variação volta a aparecer brevemente na 
Representação das variedades do português nos documentos norteadores para o ensino/aprendizagem de Português Língua Estrangeira

proposta para o curso de Português Avançado II (MINISTÉRIO DAS RELAÇÕES EXTERIORES, 2020b, p. 48), porém, mais uma vez, se recorre à nomenclatura de "variedades não prestigiadas". Na categoria de recursos lexicogramaticais, um dos pontos citados faz referência a "aspectos lexicogramaticais de variedades não prestigiadas do português brasileiro" e, na categoria correspondente recursos fonético-fonológicos, destaca-se a "identificação de fenômenos fonético-fonológicos típicos de variedades não prestigiadas do português brasileiro".

Bagno (2013, p. 65) atenta para os aspectos heterogêneos das variedades de prestígio ao afirmar que estas "apresentam certa uniformidade, mas também, como não poderia deixar de ser num território tão amplo, características próprias conforme a região [...]". Tal percepção não parece estar presente no documento em questão, visto que não há qualquer tipo de especificação sobre a quais variedades do português se faz referência e, além disso, sobre a menção a tais variedades a partir da tensão entre prestigiadas e não prestigiadas. Entendemos que um documento como esse poderia adotar uma abordagem sobre a variação que contemplasse todas as variedades do português sem estabelecer qualquer tipo de relação hierárquica entre elas.

No que se refere às variedades não brasileiras do português, só são mencionadas a partir da proposta para o Português Avançado I. Na categoria referente à dimensão sociocultural, um dos pontos citados diz respeito a "produções científicas e acadêmicas brasileiras e de outros países de língua oficial portuguesa, de diferentes áreas do conhecimento" (MINISTÉRIO DAS RELAÇÕES EXTERIORES, 2020b, p. 46).

$\mathrm{Na}$ proposta para o curso de Português Avançado II, as referências às variedades não brasileiras do português 
aparecem brevemente nas categorias de dimensão sociocultural e de recursos fonético-fonológicos, como podemos observar no quadro a seguir:

\section{Quadro 2 - Alguns pontos da proposta curricular para o curso de Português Avançado II}

\begin{tabular}{|c|c|}
\hline Dimensão sociocultural & Recursos fonético-fonológicos \\
\hline $\begin{array}{l}\text { - Produções artísticas em língua } \\
\text { portuguesa, canônicas e não } \\
\text { canônicas, em outras nações da } \\
\text { Comunidade dos Países de Língua } \\
\text { Portuguesa. }\end{array}$ & $\begin{array}{l}\text { - Aspectos lexicogramaticais de } \\
\text { variedades do português falado } \\
\text { em outras nações da Comunidade } \\
\text { dos Países de Língua Portuguesa. } \\
\text { (recursos lexicogramaticais); } \\
\text { - Identificação de fenômenos } \\
\text { fonético-fonológicos típicos de } \\
\text { variedades do português faladas } \\
\text { em outras nações da Comunidade } \\
\text { dos Países de Língua Portuguesa. }\end{array}$ \\
\hline
\end{tabular}

Fonte: Adaptado de Ministério das Relações Exteriores (2020b, p. 4849).

3.2.2 Português como língua de herança

O exemplar que tem como título Português como língua de herança (doravante PLH) se propõe a ser um documento norteador de ações pedagógicas para o ensino de PLH, de perspectiva não prescritiva e com possibilidade de adaptação a diferentes objetivos e contextos socioculturais.

A proposta apresentada é dividida em quatro habilidades - expressão oral, compreensão oral, compreensão escrita e expressão escrita - e adota um sistema de código alfanumérico a fim de auxiliar os professores no processo de identificação 

para o ensino/aprendizagem de Português Língua Estrangeira

das seguintes habilidades a serem desenvolvidas pelos alunos: expressão oral, compreensão oral, compreensão escrita e expressão escrita. $^{2}$

Em suas orientações para uso, o guia apresenta um quadro que propõe os seguintes pontos a serem abordados nas aulas: tema; subtema; funções sociais; habilidades linguísticas; componentes de conhecimento específico; exemplos/comentários; itens lexicais; pontos gramaticais.

$\mathrm{O}$ documento em questão dedica suas últimas seções às listas de tópicos a serem trabalhados, ${ }^{3}$ ressaltando sempre a flexibilidade de tais listas e enfatizando a possibilidade de complementação e adaptação para diferentes contextos e características do público-alvo.

Consideramos, inicialmente, para fins de análise, as descrições dos níveis de proficiência feitas em quadros que contemplam, além do nível curricular, a habilidade linguística, o componente de conhecimento específico e exemplos/ comentários. Na seção relativa à expressão oral, para o nível Iniciante (A1), encontramos algumas formas de referência ao português homogeneizadoras, como no seguinte exemplo: Componente de conhecimento específico: "Articular sons da língua portuguesa para ser entendido em interações simples." (MINISTÉRIO DAS RELAÇÕES EXTERIORES, 2020a, p. 32).

Tal forma de referenciação ao português parece sugerir que tal nome poderia designar, nas palavras de Faraco, "um objeto empírico uno, homogêneo, claramente delimitável..." (FARACO, 2008, p. 32). Considerando as expectativas que

\footnotetext{
2 Todos os níveis compreendem tais habilidades.

3 A quarta seção apresenta os temas transversais a serem tratados em cada nível; a quinta seção apresenta os pontos gramaticais a serem trabalhados em cada nível; a sexta seção apresenta os campos lexicais a serem explorados em cada nível; e, por fim, a sétima seção apresenta os tipos de texto a serem abordados em cada nível.
} 
um documento norteador pode gerar e o contexto de ensino do português fora do Brasil, por exemplo, podemos propor que tal referência não dá conta em absoluto das variedades do português e, como consequência, pode-se interpretar que uma aula de PLE que trate o português de maneira homogênea seja o esperado.

Essa leitura parece reforçada porque ainda, nesse mesmo quadro, o leitor encontra como exemplo/comentário a seguinte menção: "Compare os sons da língua portuguesa com os da língua do país onde o aluno mora."

Chama a atenção que tal referência apareça no primeiro nível e, após ela, se suceda a descrição dos demais níveis, que termina somente na página 155 do documento, e que nem mesmo esse tipo de referência ao português seja encontrada. Somente ao final do documento, quando se oferece uma lista de temas transversais, aparece novamente o mesmo tipo de referência ao português:

A língua portuguesa no cotidiano; A língua portuguesa no Brasil; A língua portuguesa no mundo; A língua portuguesa no país de residência; A língua do país de residência no cotidiano; A língua do país de residência no Brasil; A língua do país de residência no mundo. (MINISTÉRIO DAS RELAÇÕES EXTERIORES, 2020a, p. 155).

3.2.3 Português como língua intercultural para países de língua oficial portuguesa

$\mathrm{Na}$ apresentação da proposta deste volume, recebe grande destaque o encontro/reunião de professores e diretores de centros culturais, além de um núcleo de estudos brasileiros de países 

para o ensino/aprendizagem de Português Língua Estrangeira

de língua oficial portuguesa, que ocorreu em Luanda. O volume parece se distanciar um pouco dos outros dois anteriormente analisados em alguns aspectos que destacamos a seguir.

Encontramos referência ao caráter pluricêntrico do português e à consequente valorização de diferentes normas que vão mais além da clássica polarização entre o português do Brasil e o português de Portugal:

O surgimento de outros 'portugueses', ou a nativização do português (FIRMINO, 2015 apud TIMBANE, 2017, p. 99), indica que hoje a língua possui um caráter pluricêntrico, ou seja, há tantas normas quanto os centros em que a língua se faz obrigatoriamente presente. (BRASIL, 2020, p. 24).

O documento indica a importância de acolher todas as variedades, inclusive as locais, e propõe que seja reduzido o “distanciamento entre normas". A nosso ver, tal proposta, ausente nos documentos anteriores, traduz o verdadeiro significado da noção de pluricentrismo que, anteriormente, foi utilizada para definir o português.

Mas esse documento parece avançar no tratamento da variação no português. Ao apresentar os quadros curriculares (seção 3.3.1), há muitos outros contextos que promovem e incluem o tema da variação. Na descrição do curso "Português como Língua Intercultural Básico A1”, por exemplo, no início da ementa, já se destaca a relevância do tema ao propor o reconhecimento da diversidade linguística no espaço lusófono a partir da conscientização sobre a existência de normas emergentes da língua portuguesa e sua relação com as identidades regionais" (MINISTÉRIO DAS RELAÇÕES EXTERIORES, 2020c, p. 41).

O Quadro 5, Proposta de currículo para o referido curso, 
apresenta um detalhamento ao descrever temas, gêneros discursivos, tarefas/projetos e conteúdos estruturantes. Os dois temas propostos são sumamente favorecedores de aulas inclusivas e input que considere diferentes variedades do português. Ao proporem o tema "Conscientização sobre a língua que se fala (que português eu falo?)" ou o tema "Aspectos identitários ligados à variedade linguística", norteiam, sem dúvida, o professor a se informar e buscar input que permita tal problematização em sua sala de aula.

Entretanto, a combinação dos demais elementos que compõem a proposta curricular não necessariamente parece conversar com os temas. Assim, se consideramos a sugestão de conteúdos estruturantes para os dois temas, não vemos necessariamente referências mais detalhadas, para o professor, dos elementos que podem ser explorados para tratar o tema, como, por exemplo, a distribuição dos pronomes "nós" e "a gente" a que nos referimos na parte inicial deste artigo.

Se avançamos um pouco mais na análise das descrições dos conteúdos estruturantes, ainda encontramos marcas de uma tradicional neutralização das variedades do português, ao levantarmos referências tais como: "Familiarização com o quadro fonético-fonológico do português do Brasil em contraste com o português europeu e variantes regionais". Ao longo do documento, são inúmeras as ocorrências que podemos levantar de tal tendência.

Talvez por se tratar de uma primeira sistematização, o documento não pretenda tratar exaustivamente o tema, mas, ao se propor como documento de referência, seria importante minimamente sugerir estudos sobre os temas, como leitura complementar para o professor. 
Representação das variedades do português nos documentos norteadores para o ensino/aprendizagem de Português Língua Estrangeira

Em outros níveis, as referências começam a ser mais escassas, embora tampouco haja informação suficiente para $o$ professor, e tal maneira de referenciar as variedades do português pudesse ser feita de forma mais linguística e acadêmica ("mineirês, gauchês") (MINISTÉRIO DAS RELAÇÕES EXTERIORES, 2020c, p. 44), porque podem inclusive reforçar alguns estereótipos.

No Quadro 7, que apresenta a proposta de currículo para o curso de Português como Língua Intercultural Intermediário $\mathrm{B} 1$, um dos conteúdos estruturantes diz respeito à colocação pronominal e inclui os três tipos de colocação: próclise, mesóclise e ênclise (MINISTÉRIO DAS RELAÇÕES EXTERIORES, 2020c, p. 45). O professor que teve como única formação o próprio curso de português poderá encaminhar o tema sem necessariamente considerar os estudos sobre a redução do sistema pronominal do português do Brasil, por exemplo.

Destacamos ainda o Quadro 10, que apresenta a proposta de currículo para o curso de "Português como Língua Intercultural Avançado C2", na qual encontramos, na descrição dos conteúdos estruturantes, uma referência a "influências do português europeu e/ou do Brasil na norma do português local", que parece sugerir uma hierarquização das variedades estándares sobre as demais variedades que são nomeadas como "locais".

Considerando o panorama exposto relativo a esse documento, nosso entusiasmo inicial ao encontrar a voz da variação no português parece que foi silenciado nos demais níveis, como se o tema se exaurisse em poucas aulas. Da mesma forma, entendemos que as demais seções da proposta ainda estão mais vinculadas a propostas mais conteudísticas, que não favorecem a inclusão da variação em toda a formação linguística. 


\section{Considerações finais}

Partimos inicialmente do pressuposto de que dizer "português", a partir de Faraco (2008), não representa uma realidade homogênea e delimitável e que, no que diz respeito ao português, reúne um universo de múltiplas variedades dentro de cada um dos países que têm essa língua como oficial.

Considerando o universo múltiplo que constitui o contexto de ensino/aprendizagem de PLE, de diferentes demandas, recursos e professores com formação mais ou menos especializada, entendemos a importância de ações políticas que deem aos diferentes agentes do processo condições de ensinar e aprender, se preparar para ser avaliado e quaisquer outros objetivos que se estabeleçam no processo.

Neste artigo, ao nos propor a analisar os documentos norteadores para o PLE, analisamos inicialmente o Documentobase do Exame Celpe-Bras (BRASIL, 2020), tendo em vista que muitos estudos afirmam que tal documento se constitui como referência no ensino de PLE, ao não haver outros documentos. Considerando a natureza e finalidade do documento, não encontramos referências às variedades do português e, portanto, entendemos que tal ação tenha seu escopo limitado à avaliação de proficiência.

Encontramos uma série do Ministério de Relações Exteriores desenhada especificamente para o PLE que foi publicada em 2020 e selecionamos três dos cinco volumes para nossa análise. Entendemos a importância e relevância de tal ação, considerando seu ineditismo, mas nossa análise nos permite afirmar que as referências às variedades do português ainda são bastante tímidas. Entendemos que talvez tais documentos 
Representação das variedades do português nos documentos norteadores para o ensino/aprendizagem de Português Língua Estrangeira

pudessem sugerir alguns dos muitos estudos que têm sido feitos e que dão conta de diferentes fenômenos do PLE como leituras complementares para que (ainda que inicialmente) a variação seja uma pauta incluída no processo de ensino/aprendizagem de PLE.

Reconhecemos que a coleção organizada pelo Ministério de Relações Exteriores voltada para o ensino de PLE, bem como a nova versão do Documento-base do Exame CelpeBras (BRASIL, 2020) nos permitem comemorar pequenos avanços na direção de uma política linguística mais atuante no que diz respeito ao ensino-aprendizagem de PLE. Entretanto, há ainda muitas lacunas, principalmente, no que diz respeito à representação do PB e suas variedades.

Seria interessante que novas ações pudessem ser implementadas no sentido de fornecer subsídios para os diferentes agentes do processo, tais como professores e aprendizes. Eque tais ações pudessem ser planejadas por equipes multidisciplinares, que contribuiriam com diferentes especialidades na elaboração de materiais mais completos.

\section{Referências}

AZEREDO, J. C. Gramática Houaiss da Língua Portuguesa. 2. Ed. São Paulo: Publifolha, 2008.

BAGNO, Marcos. Sete erros aos quatro ventos: a variação linguística no ensino de Português. São Paulo: Parábola Editorial, 2013.

BAGNO, Marcos. Dicionário crítico de sociolinguística. São Paulo: Parábola, 2017. 
Representação das variedades do português nos documentos norteadores para o ensino/aprendizagem de Português Língua Estrangeira

BAKHTIN, Mikhail. (1979). Estética da criação verbal. Tradução Paulo Bezerra. 4. ed. São Paulo: Martins Fontes, 2003. BAKHTIN, Mikhail. (1975). Questões de Literatura e de Estética: a teoria do romance. Tradução Aurora Fornoni Bernardini et. al. 5. ed. São Paulo: Hucitec, 2002.

BRASIL. Documento-base do Exame Celpe-Bras. Brasília: INEP, 2020. Disponível em: <https://download.inep.gov.br/ publicacoes/institucionais/avaliacoes_e_exames_da_educacao basica/documento_base_do_exame_celpe_bras.pdf $>$. Acesso em: 23 fev. 2021.

CALVET, Louis-Jean. Sociolinguística: uma introdução crítica. Tradução Marcos Marcionilo. 2. ed. rev. São Paulo: Parábola Editorial, 2002.

CARVALHO, Orlene Lúcia de S.; BAGNO, Marcos. Variação linguística e ensino: 'nós' e 'a gente' em livros didáticos de português brasileiro como língua estrangeira. Revista de Estudios Portugueses y Brasileos, [s. l], v. 15, p. 25-40, 2017. CASTILHO, Ataliba T. de. Nova gramática do português brasileiro. São Paulo: Editora Contexto, 2010. CONSELHO DA EUROPA. Quadro europeu comum de referência para as línguas: aprendizagem, ensino, avaliação. Tradução Maria Joana Pimentel do Rosário e Nuno Verdial Soares. Porto: Edições Asa, 2001.

FARACO, Carlos Alberto. Norma culta brasileira: desatando alguns nós. São Paulo: Parábola Editorial, 2008.

FRANCO, Gabriele. A interculturalidade no ensino de PLE: metodologias ativas e políticas linguísticas. Estudos Linguísticos (São Paulo. 1978), São Paulo, v. 48, n. 3, p. 1.3861.399, dez. 2019. Disponível em: <https://revistas.gel.org.br/ estudos-linguisticos/article/viewFile/2220/1604>. Acesso em: 15 fev. 2021. 
Representação das variedades do português nos documentos norteadores para o ensino/aprendizagem de Português Língua Estrangeira

MINISTÉRIO DAS RELAÇÕES EXTERIORES. Proposta curricular para o ensino de português como língua de herança. Brasília: Funag, 2020a. Disponível em: <http://funag. gov.br/biblioteca/index.php?route=product/product\&product $\mathrm{id}=1027 \#: \sim:$ text $=$ Esta $\% 20$ proposta $\% 20 \% \mathrm{C} 3 \% \mathrm{~A} 9 \% 20$ um $\% 20$ documento,com $\% 20$ presen $\%$ C3\%A $7 \mathrm{a} \% 20 \mathrm{de} \% 20$ imigrantes\%20brasileiros $>$. Acesso em: 23 fev. 2021.

MINISTÉRIO DAS RELAÇÕES EXTERIORES. Proposta curricular para o ensino de português nas unidades da rede de ensino do Itamaraty em países de língua oficial espanhola. Brasília: Funag, 2020b. Disponível em: $<$ http://funag.gov.br/biblioteca/index.php?route=product/ product\&product_id=1023\#: :text=Trata $\% 2$ Dse $\% 20 \mathrm{de} \% 20$ um $\% 20$ projeto,como $\% 20$ (uma) $\% 201 \%$ C 3\%ADngua $\% 20$ oficial>. Acesso em: 23 fev. 2021.

MINISTÉRIO DAS RELAÇÕES EXTERIORES. Proposta curricular para o ensino de português nas unidades da rede de ensino do Itamaraty em países de língua oficial portuguesa. Brasília: Funag, 2020c. Disponível em: <http://funag.gov. $\mathrm{br} / \mathrm{biblioteca} /$ index.php? route $=$ product/product\&product id $=1024>$. Acesso em: 23 fev. 2021.

NEVES, M. H. M. A gramática funcional. São Paulo: Martins Fontes, 2001.

NIEDERAUER, Marcia. Competência interacional: critério para avaliação da produção oral em língua adicional. Trabalhos em Linguística Aplicada, Campinas, v. 53, n. 2, p. 403-424, jul./dez. 2014.

NUNES, Elaine C. Roschel; LORKE, Franziska. O problema da adequação dos parâmetros do Quadro Europeu Comum de Referência e "a necessidade de emergir como os outros de nós mesmos". Revista X, Curitiba, v. 2, n. 1, p. 40-60, 2011. Disponível em: <https://revistas.ufpr.br/revistax/article/ view/22892/17679>. Acesso em: 4 mar. 2021. 
Representação das variedades do português nos documentos norteadores para o ensino/aprendizagem de Português Língua Estrangeira

PERINI, M. A.. Gramática do português brasileiro. São Paulo: Parábola Ed., 2010.

SCHOFFEN, Juliana Roquele; MARTINS, Alexandre Ferreira. Políticas linguísticas e definição de parâmetros para o ensino de português como língua adicional: perspectivas portuguesa e brasileira. ReVEL, [s. l.]. v. 14, n. 26, p. 271306, mar. 2016. Disponível em: <http://www.revel.inf.br/files/ c35e818efe36c34dda7b55fdcf72b0fe.pdf $>$. Acesso em: $13 \mathrm{fev}$. 2021.

SERRANI, Silvana. Discurso e cultura na aula de língua: currículo, leitura, escrita. Campinas: Pontes, 2010.

SILVA, Tomaz Tadeu da. A produção social da identidade e da diferença. In: SILVA, Tomaz Tadeu da; HALL, Stuart; WOODWARD, Kathryn. Identidade e diferença: a perspectiva dos estudos culturais. Petrópolis: Vozes, 2000. Cap. 2, p. 73-102. 